\title{
The Seismic-Geological Comprehensive Prediction Method of the Low Permeability Calcareous Sandstone Reservoir
}

\author{
Hongyan Jiao*, Zhiying Ding \\ College of Petroleum Engineering, China University of Petroleum, Qingdao, China \\ Email: jiaohy_slyt@126.com
}

Received 3 June 2016; accepted 9 August 2016; published 12 August 2016

Copyright $@ 2016$ by authors and Scientific Research Publishing Inc.

This work is licensed under the Creative Commons Attribution International License (CC BY).

http://creativecommons.org/licenses/by/4.0/

(c) (i) Open Access

\section{Abstract}

Currently in Niu-zhuang sub-sag, the seismic reflection amplitude of the newly discovered turbidite sandstone is stronger in the third Segment. The main reason is that Calcareous components accounts for a large part and physical properties is relatively poor, which results in no corresponding relation between reservoir and seismic attributes, and effective reservoir is difficult to predict and describe. Therefore, using the method of geological statistics, we firstly study the distribution of calcareous matters, secondly study the contribution to seismic reflection amplitude made by Calcareous high impedance component; thirdly analyze its influence on actual seismic reflection amplitude and determine the lithology thickness of Calcareous via replacement forward modeling. At last, we characterize the reservoir using the amplitude of calcareous matters. It proves that the method of seismic-geological comprehensive prediction is reliable. It has good guidance for exploration and development of the calcareous sand lithologic reservoir in similar areas.

\section{Keywords}

Calcareous Sand-Stone, Geostatistical, Reflection Amplitude, Calcareous Forward Modeling, Reservoir Prediction

\section{Introduction}

Niu-zhuang sub-sag is located in the middle part of Dongying concave. Dongying central uplift zone is in the north and Dongying southern slope is in the south. Its area is about $400 \mathrm{~km}^{2}$. The major oil-bearing series is the

\footnotetext{
${ }^{*}$ Corresponding author.
}

How to cite this paper: Jiao, H.Y. and Ding, Z.Y. (2016) The Seismic-Geological Comprehensive Prediction Method of the Low Permeability Calcareous Sandstone Reservoir. Open Journal of Geology, 6, 757-762.

http://dx.doi.org/10.4236/ojg.2016.68058 
third segment of Shahejie group in the third series which is a part of Dongying delta front. Its features are fast propulsion, continuous accretion, big angle of foreset slope, sediment to slump and turbidite sand body development. The third segment of Niu-zhuang sub-sag has been explored and developed highly and the undiscovered lithologic oil-gas reservoir has stronger concealment. From the point of drill encounter situation of drilled well, newfound sand body shows the stronger seismic reflection amplitude [1]-[3]. It is thought that there is high impedance which is not influenced by reservoir factor. The main reason is that rock components are complex, calcareous components are more; horizontal distributions are regional and transverse thickness is variational. So the reservoir identification is influenced by regional and lateral heterogeneity which makes the prediction and description of effective reservoir very difficult [4]-[7]. Based on the vast geostatistics analysis, this paper considers the feature of the third segment that the calcareous is corresponded to the reservoir lithology impedance, studies and analyzes the seismic attribute after removing the influence of calcareous, macroscopicly summarizes the change rule between seismic attribute and reservoir thickness, establishes the empirical formula of reservoir parameter, and forms the seismic prediction method of similar calcareous turbidite sand body reservoir. The effect is obvious after application.

\section{Confirm the Development and Distribution of Calcareous by Geostatistics}

For the third segment of Niu-zhuang sub-sag, after demarcating the seismic acoustic record according to the real drilling data, It is found that high impedance components is not influenced by reservoir factor as shown by gray label in Figure 1 and Figure 2. But calcareous and sericite components in rocks. More specifically that is calcareous fine siltstone, oil shale, sericite fine sandstone and so on. The reservoir identification is influenced by the regional horizontal distribution of calcareous and sericite components and the variational transverse thickness.

According to the real drilling statistics and seismic attribute analysis, the first reservoir calcareous in the third segment is taken as example which is mainly located in the mid-east region of work area in the plane and distributed in the high amplitude zone laterally, such as $35 \mathrm{~m}$ of wang62 and $44 \mathrm{~m}$ of wang581. The horizontal distribution is heterogeneous which influences the amplitude, so the thickness distribution in the plane can be derived reversely according to the geological analysis and the seismic attribute (Figure 3).

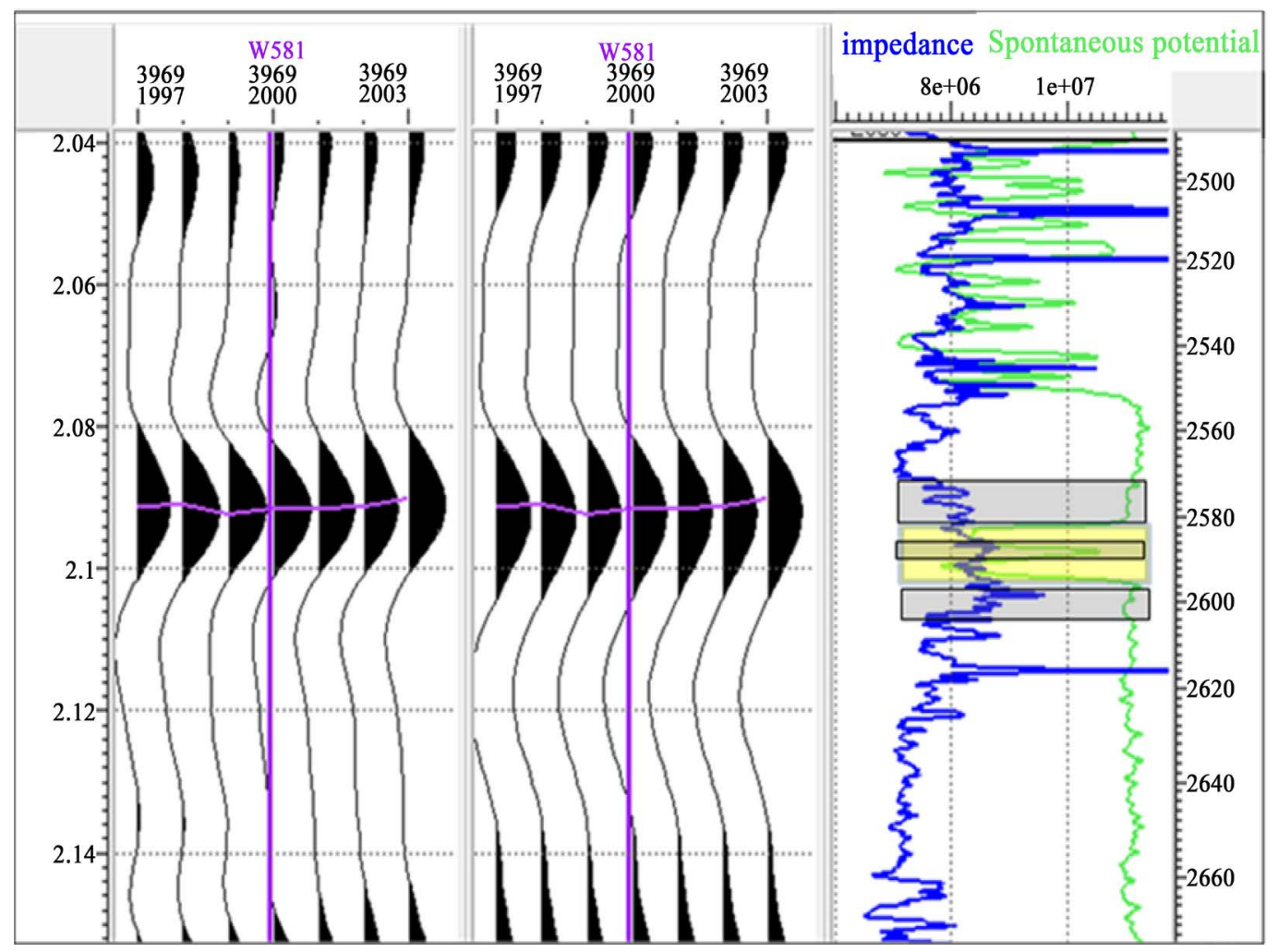

Figure 1. Labeled graph of lithological association in reservoir segment of well W581. 


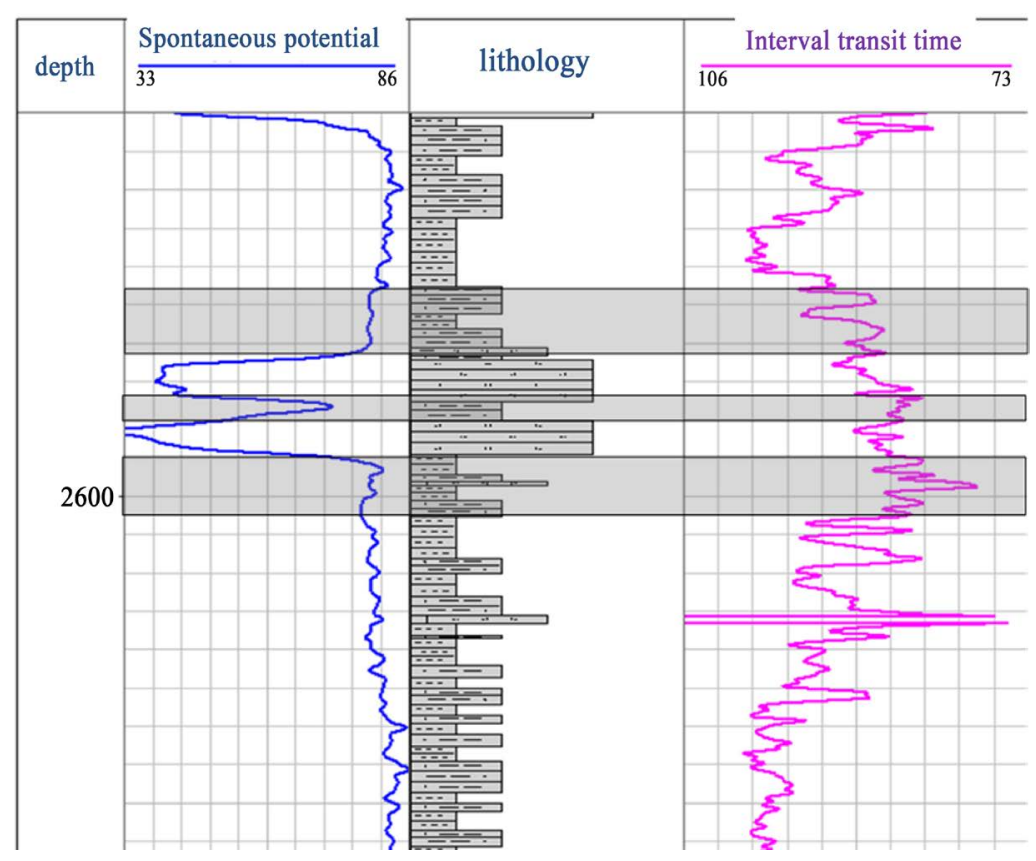

Figure 2. Comprehensive bar graph in reservoir segment of well W581.

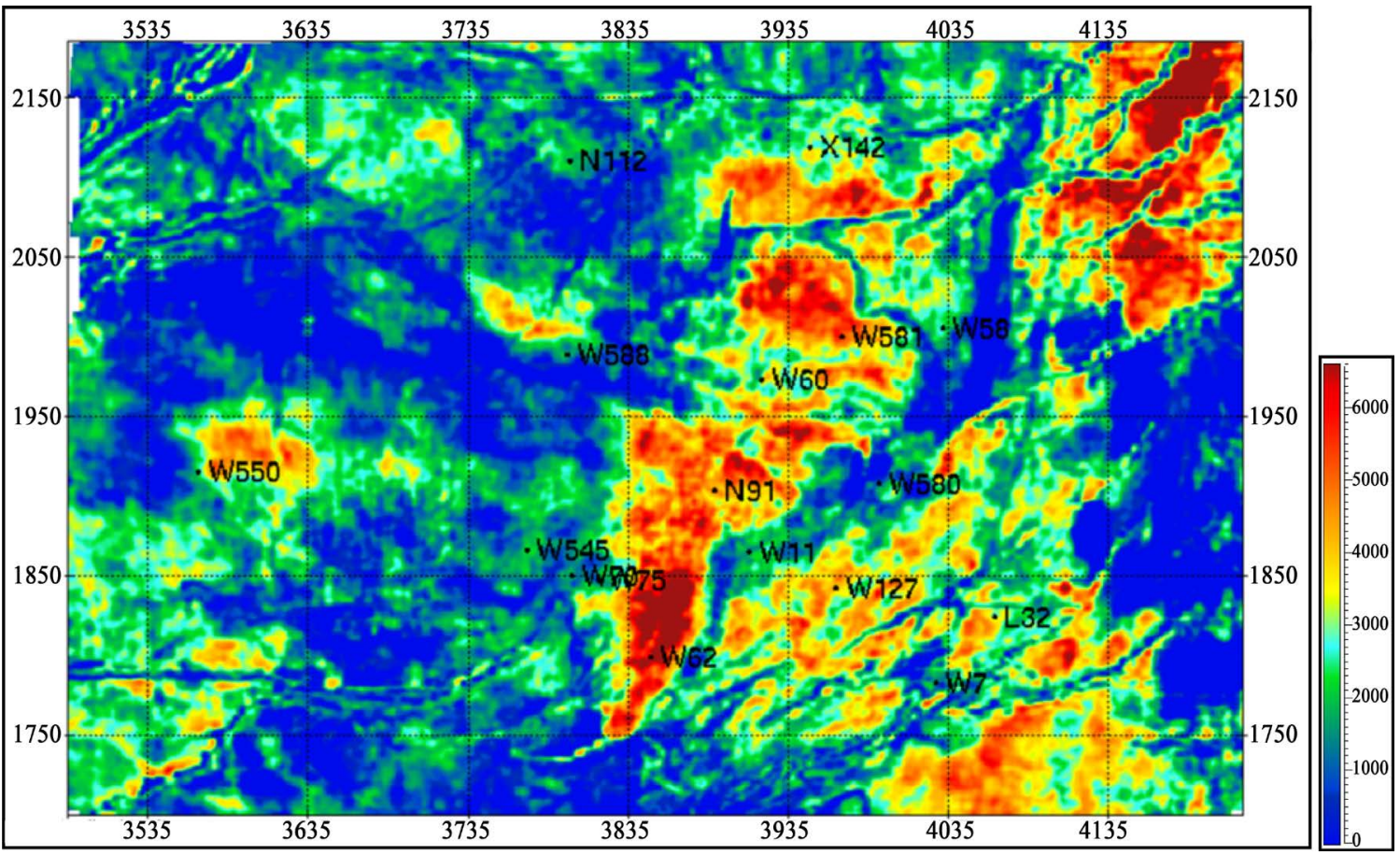

Figure 3. Amplitude attribute of reservoir top surface in the third segment.

\section{The Relationship between the Thickness of High Impedance Rocks and Amplitude Statistics}

On the basic of the impact factor of high impedance, the influence of amplitude and impedance affected by calcareous components is analyzed through the relationship between reservoir thickness and amplitude in affected zone (inside the red line in Figure 3) and the relationship between reservoir thickness and amplitude out of the affected zone. The result shows that for the $10 \mathrm{~m}$-thickness reservoirs the amplitude is about $2000 \mu \mathrm{m}$ out of the 
calcareous affected zone, the amplitude is about $6000 \mu \mathrm{m}$ in the calcareous affected zone and the high impedance components such as calcareous contribute about $4000 \mu \mathrm{m}$ from the statistics of reservoir thickness, seismic amplitude, impedance of more than 30 wells. For reservoirs whose thickness is $5 \mathrm{~m}$, calcareous high impedance components contribute about $2900 \mu \mathrm{m}$.

There are two obvious relation formulas between rock thickness and amplitude for high impedance components. This indicates the intercept of calcareous rock thickness is larger than that of reservoir obviously. Figure 4 shows the relation formula between high impedance thickness and amplitude in reservoir, where 1) is the relation formula between reservoir thickness and amplitude without calcareous effect, and 2) is the relation formula between reservoir thickness and amplitude including the calcareous effect.

So the effect of high impedance such as calcareous must be eliminated before predicting the reservoir and the thickness di.

\section{Reservoir Characterization Using Amplitude without Calcareous Effect}

On the basic of the geological distribution of calcareous components and the effect to impedance, 19 typical wells were chosen to do forward modeling after eliminating calcareous components and the rock thickness of calcareous components is calculated through the difference of the amplitude. Then the relationship of calcareous thickness and the amplitude is established.

$$
\mathrm{Y}=684.3 \mathrm{e}^{0.038 \mathrm{X}}
$$

where $\mathrm{X}$ is the thickness of calcareous, $\mathrm{m}, \mathrm{Y}$ is the affected amplitude (the difference between real seismic amplitude and replacement amplitude), $\mu \mathrm{m}$. The relationship is exponent. The more the calcareous is, the larger the effect on amplitude is (Figure 5).

The calcareous thickness is determined through geological analysis method in the early stage. The background amplitude affected by calcareous components is established which is in contrast with the original seismic reflection amplitude, then standard reflection amplitude attribute is obtained after eliminating calcareous effect (Figure 6).

The amplitude attribute revised by calcareous background field can be used to predict macro-distribution of reservoir for the uniform color scale. The reservoir distribution has feature of turbidite sand body, and the boundary of amplitude is more clear in the main calcareous affected zone (red area in Figure 6). In zones without calcareous effect (north of wang545), the reservoir development can be represented while former respond of

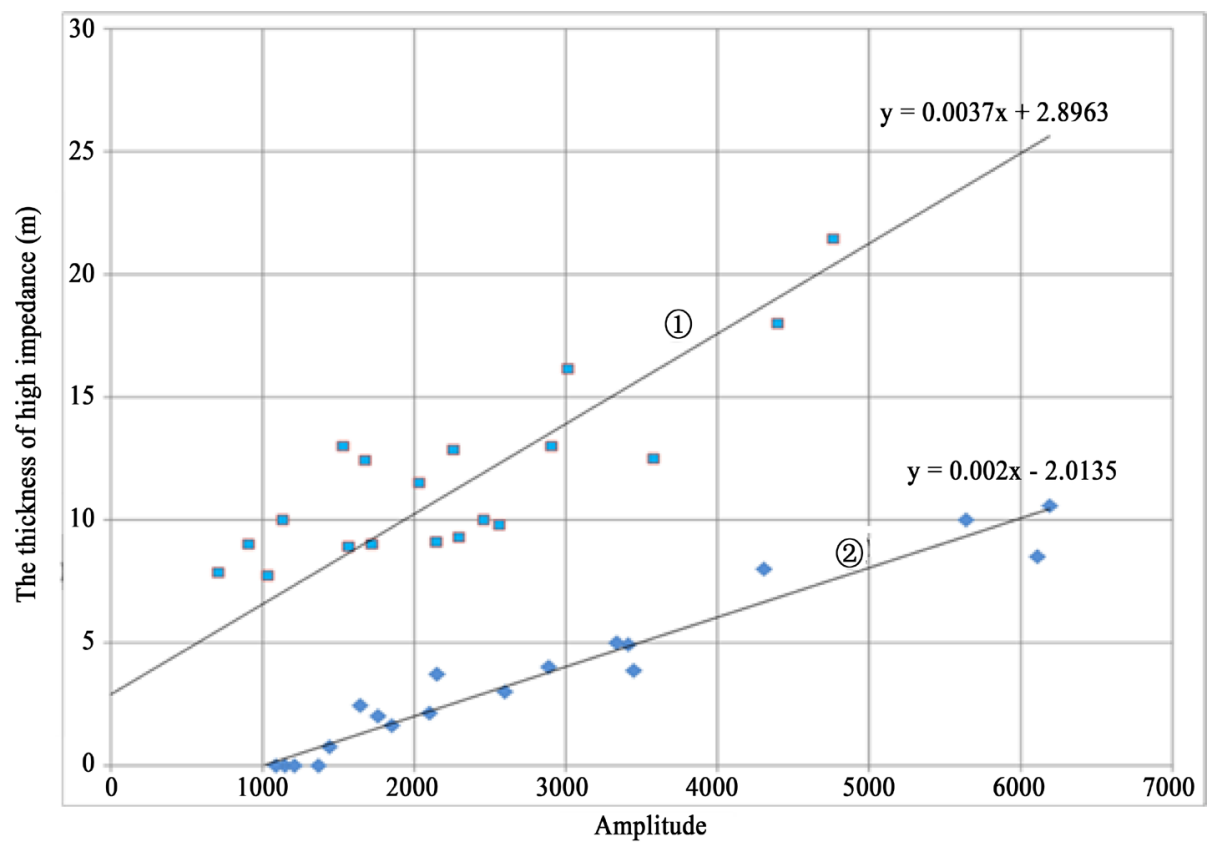

Figure 4. The relationship between high impedance rock thickness and amplitude in reservoir of the third segment. 


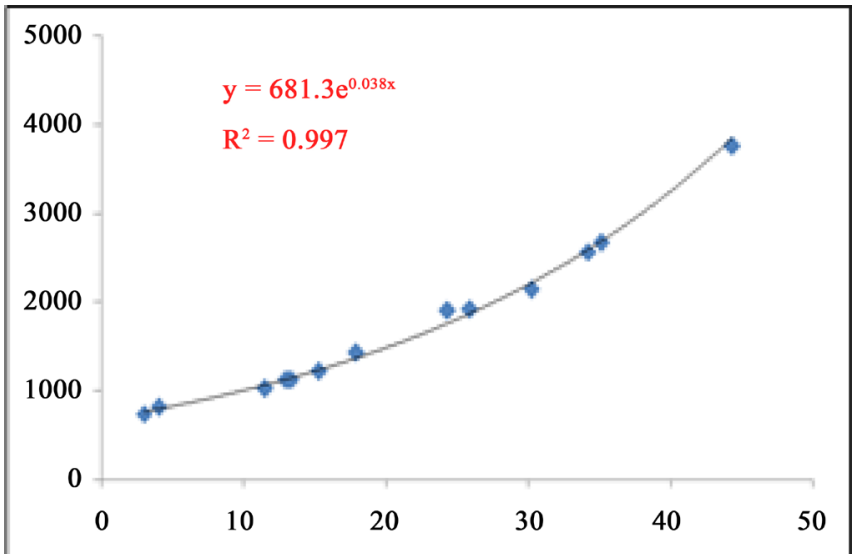

Figure 5. The relationship between the calcareous thickness and the affected amplitude.

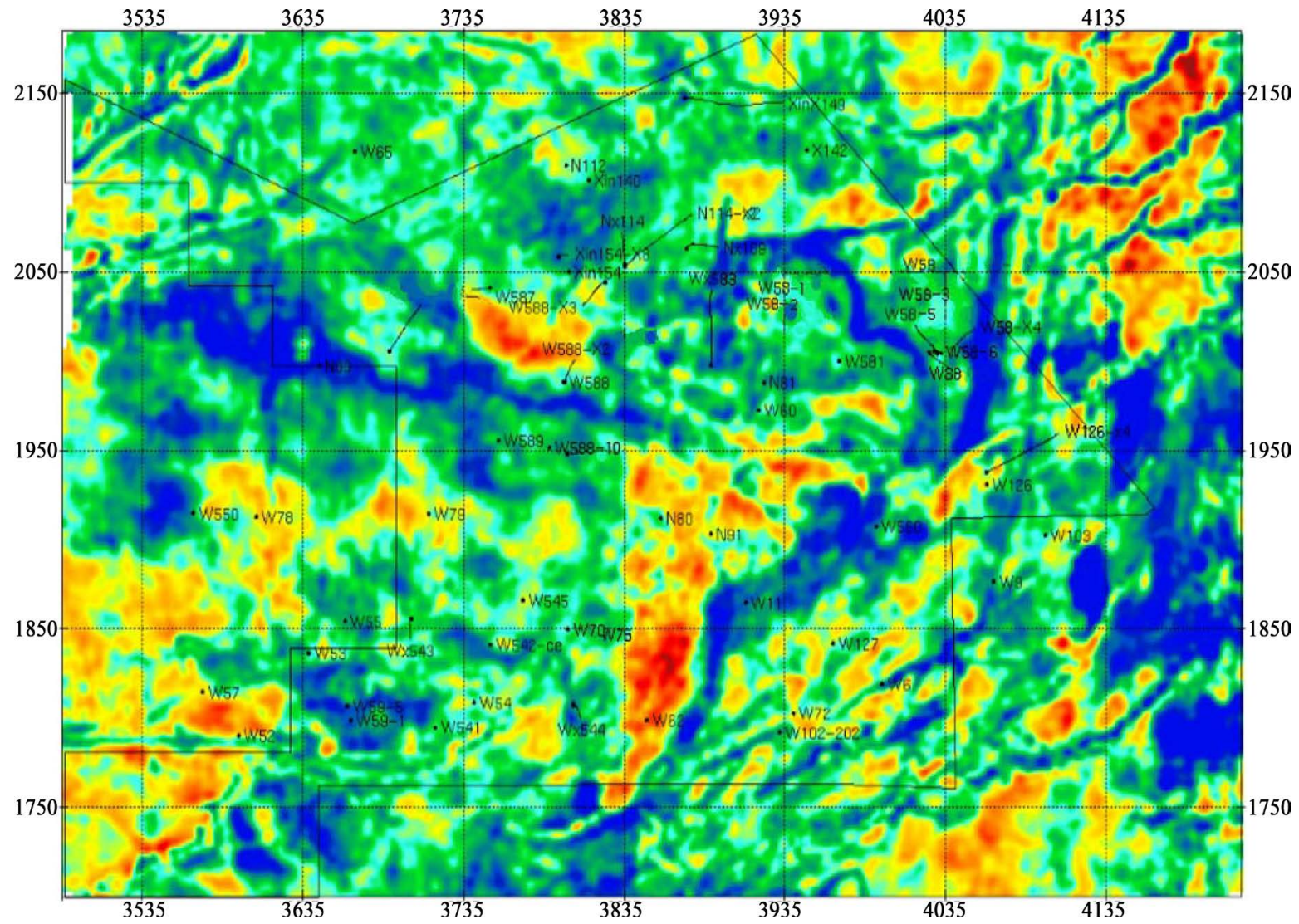

Figure 6. Plane figure (after correction) (right) of maximum amplitude attribute of the top in reservoir Es3z6.

reservoir is not obvious because of the calcareous components. And the representation is identical with the real drilling. The analysis above shows that the effect of this inversion profile can conform to geological sedimentary rule and describe the sandstone clearly.

\section{Results and Discussions}

Here are the results and discussions.

1) The effective, comprehensive and objective relationship between reservoir parameter and seismic attribute is the basis of lithologic reservoir prediction by using seismic attribute. It is important to recognize the seismic 
reflection of lithologic reservoir, and capture the attribute which can reflect the reservoir feature.

2) Geosciences statistics results have certain macroscopic guiding significance for exploration of complex lithologic reservoir. But the results are qualitative. Only there are a certain number of parameters and constraint of macro-planar characteristics, quantitative computing of reservoir parameter feature can be achieved through statistics. Usually the quantitative computing results of reservoir physical properties are dynamic. On one hand, it can direct the exploration and development of lithologic reservoir, on the other hand, this relationship can be revised according to the new drilling accomplishments continually, and consequently improve the prediction accuracy.

3) Under the restrictions of seismic resolution, usually the prediction results of lithologic reservoir using seismic attribute are circumscribed, specific, and multiple. So pursuing universality and high precision of prediction method and computing model cannot meet the requirement of practical production. Only seriously analyzing real geological condition and seismic data, building the correct geological model, and studying the prediction method which conform to give local geological rule, better prediction effect of reservoir property can be obtain.

\section{Acknowledgements}

This work was supported by the Program for Changjiang Scholars and Innovative Research Team in University (IRT1294) and the China National Science and Technology Major Projects (Grant No.: 2016ZX05011).

\section{References}

[1] Wang, H.Y., Fan, T.L. and Xiao, Y.Y. (2010) Effect of Tuffaceous Components on Physical Property of Sandstone Reservoir. ACTA Petrolei Sinica, 31.

[2] Li, X.G., Shao, J.H. and Zhang, T. (2004) The Application of Wave Impedance Model Forward Technique in Sandstone Reservoir Prediction. Geophysical Prospecting for Petroleum, 43.

[3] Cao, H. (2004) The Discussing of Several Key Questions in Seismic Attribute Application. Geophysical Prospecting for Petroleum, 43.

[4] Li, Q.Z. (1993) The Road towards to Accurate Exploration. Petroleum Industry Press, Beijing.

[5] Liu, W.L. (1995) Oil-Gas Field Development Seismic Technique. Petroleum Industry Press, Beijing.

[6] Wang, Y.M., et al. (2001) Predicting Reservoir by Using Seismic Attribute Technique in A Area. Geophysical Prospecting for Petroleum, $\mathbf{4 0 .}$

[7] Xiong, Z. (1995) Systematic Thought of Seismic Data Processing Method. Petroleum Industry Press, Beijing.

\section{Submit or recommend next manuscript to SCIRP and we will provide best service for you:}

Accepting pre-submission inquiries through Email, Facebook, LinkedIn, Twitter, etc.

A wide selection of journals (inclusive of 9 subjects, more than 200 journals)

Providing 24-hour high-quality service

User-friendly online submission system

Fair and swift peer-review system

Efficient typesetting and proofreading procedure

Display of the result of downloads and visits, as well as the number of cited articles

Maximum dissemination of your research work

Submit your manuscript at: http://papersubmission.scirp.org/ 